\title{
VOLUMETRIC LEAD ASSAY
}

Principal Investigator:

M. A. Ebadian, Ph.D.

Florida International University

Collaborators:

S.K. Dua

David Roelant

Sachin Kumar

Prepared for:

U.S. Department of Energy Office of Environmental Management Office of Science and Technology

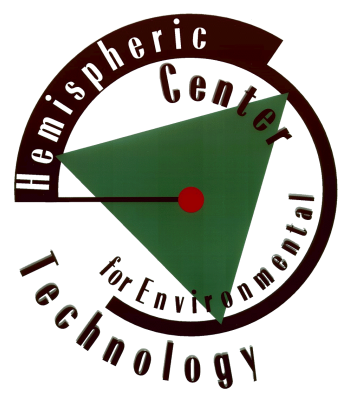




\section{DISCLAIMER}

This report was prepared as an account of work sponsored by an agency of the United States government. Neither the United States government nor any agency thereof, nor any of their employees, nor any of its contractors, subcontractors, nor their employees makes any warranty, express or implied, or assumes any legal liability or responsibility for the accuracy, completeness, or usefulness of any information, apparatus, product, or process disclosed, or represents that its use would not infringe upon privately owned rights. Reference herein to any specific commercial product, process, or service by trade name, trademark, manufacturer, or otherwise does not necessarily constitute or imply its endorsement, recommendation, or favoring by the United States government or any agency thereof. The views and opinions of authors expressed herein do not necessarily state or reflect those of the United States government or any agency thereof. 


\section{VOLUMETRIC LEAD ASSAY}

\section{Principal Investigator}

M.A. Ebadian, Ph.D.

Hemispheric Center for Environmental Technology

Florida International University

Miami, FL 33174

\section{Florida International University Collaborators}

S.K. Dua, Ph.D.; David Roelant, Ph.D.; Sachin Kumar Hemispheric Center for Environmental Technology

Florida International University

Miami, FL 33174

January 2001

\section{Prepared for}

U.S. Department of Energy

Office of Environmental Management

Office of Science and Technology

U.S. Department of Energy

Under Grant No DE-FG21-95EW55094 



\section{ACKNOWLEDGMENTS}

This report is based on work supported by the U.S. Department of Energy, Office of Environmental Management, Office of Science and Technology's Deactivation and Decommissioning Focus Area, National Energy Technology Laboratory. The Principal Investigator, FIU Collaborators, and students at Florida International University would like to thank Dr. Paul Hart, Bob Bedick, and Steven Bossart for their support and encouragement on this project. 



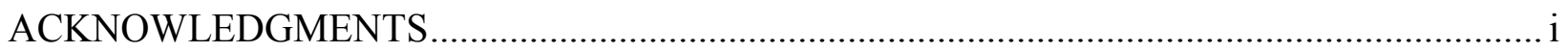

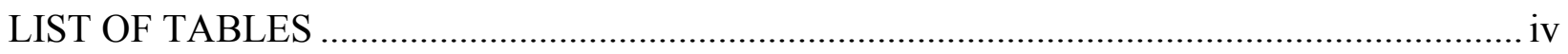

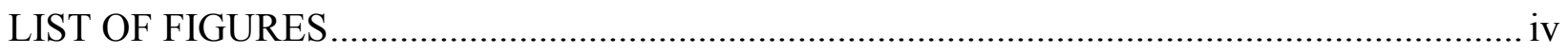

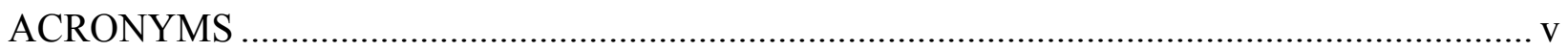

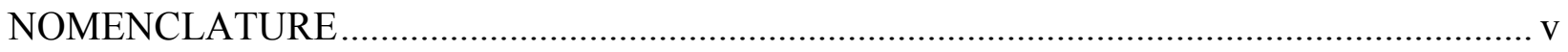

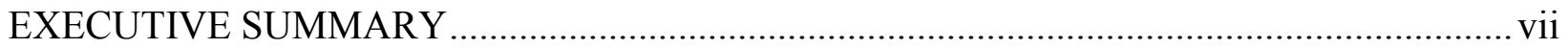

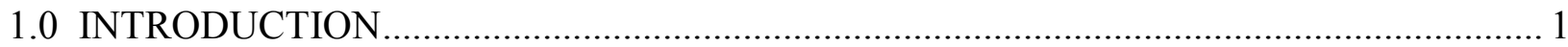

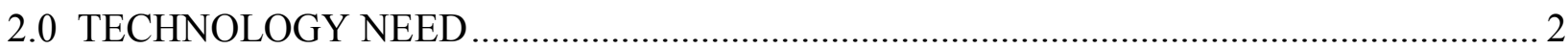

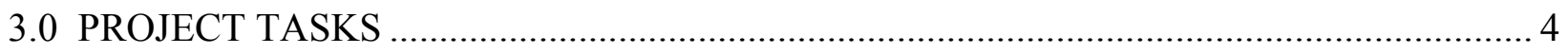

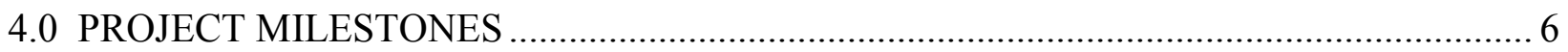

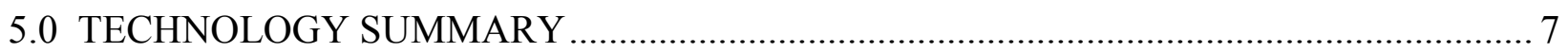

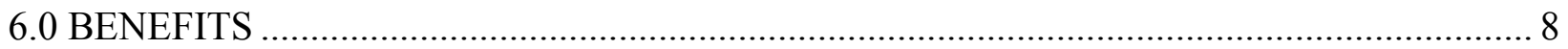

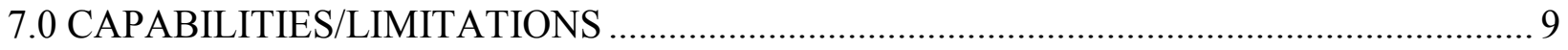

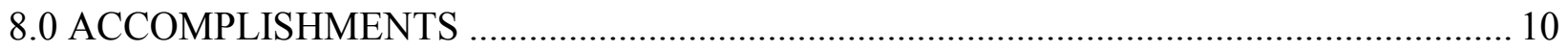

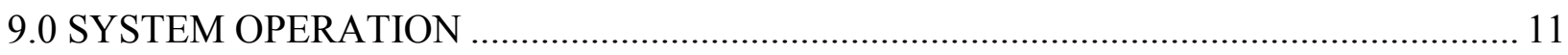

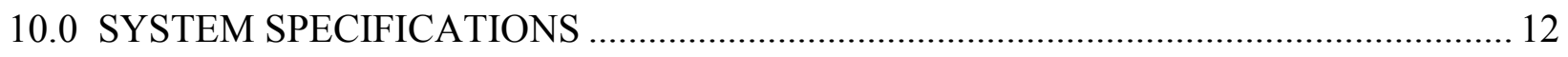

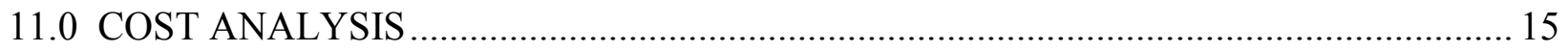

Appendix A: Schematic Cost Structure and Profit Margin for Volumetric Lead Assay System

Appendix B: Four Detectors and Accessories Quoted by Canberra

Appendix C: Contact Information 


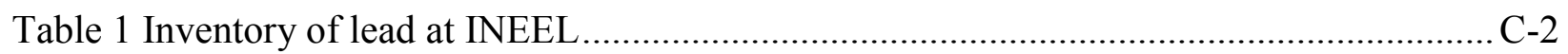

Table 2 Summary of contamination values for unrestrictive free release ..................................

Table 3 List of instruments used by INEEL technicians.......................................................... C-3

\section{LIST OF FIGURES}

Fig. 1 Volumetric lead assay system, showing a robotic system, conveyor, characterization system, and lead collection containers. .............................................................................. 11

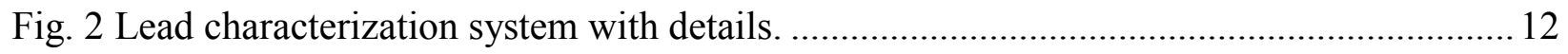

Fig. 3 Gamma spectrum obtained by placing a Co-60 standard source at a distance from the BEGe detector, showing Co- 60 peaks, in addition to natural background radionuclides... C-4

Fig. 4 Gamma spectrum obtained by placing a 12"x 4 "x2" thick lead brick at a distance from the BEGe detector, showing natural background radionuclides. ............................................

Fig. 5 Gamma spectrum obtained by placing 8 "x8"x 0.25 " thick lead wool at a distance from the BEGe detector, showing natural background radionuclides. C-6 
BEGe Broad Energy Germanium

CMST-CP Characterization, Monitoring, and Sensor Technology Crosscutting Program

D\&D Deactivation and Decommissioning

DOE U.S. Department of Energy

DOE-EM U.S. Department of Energy-Environmental Management

DOE-OST U.S. Department of Energy-Office of Science and Technology

FIU Florida International University

FIU-HCET Florida International University's Hemispheric Center for Environmental Technology

FY00 Fiscal Year 2000

HCET Hemispheric Center for Environmental Technology

INEEL Idaho National Engineering and Environmental Laboratory

ISOCS In-situ object counting system

$\mathrm{pCi} \quad$ Pico Curie

RCRA Resource Conservation and Recovery Act

psi pounds per square inch

$\mathrm{ft}$ foot

V volt

Amp ampere 



\section{EXECUTIVE SUMMARY}

Lead in the form of shot, bricks, plates, and sheeting was and is used as shielding at all DOE sites to reduce worker exposure from gamma emitting radionuclides. Lead forms can become surface contaminated during their use in radioactive areas. They can also become volume contaminated as a result of being formed from surface contaminated lead or as a result of activation in shielding conditions. At many of the DOE sites, for example, Idaho National Engineering and Environmental Laboratory (INEEL), lead is present in far greater quantities than needed for emergency use. Resource Conservation and Recovery Act (RCRA) requires lead to be managed as a hazardous waste if it is no longer providing its intended use. Lead contaminated with radioactive materials must be treated as mixed waste. Disposal of mixed waste is very expensive.

Most of the lead is not expected to be radioactively contaminated. If it can be demonstrated that a significant part of the lead is not contaminated, then instead of disposing it as mixed waste, it can be recycled as a scrap metal, earning revenue, thus providing a significant saving on disposal costs. The traditional contamination survey techniques are not effective in surveying the internal volume of lead forms due to the self-shielding attributes of lead. Current characterization techniques for determining internal volume contamination, requiring physical samples to be extracted from the interior volume of lead items, and laboratory analysis are expensive, timeconsuming, and do not provide $100 \%$ lead item sampling and do not meet the DOE's mission of accelerated, safe, and cost-effective cleanup.

An alternative method for characterization and handling of large quantities of lead is proposed. Initially, it is intended for lead bricks. Later, its application can be extended to other lead forms. The method is based on an automated system requiring minimum amount of manpower, thus reducing exposure of human beings to radiation or to airborne lead particles. The system consists of a robotic gripper that picks up lead bricks from a stack and places them on a conveyor. Lead is characterized by a gamma spectrometer using Broad Energy Germanium detectors. In-Situ Object Counting System software is used for determination of the counting efficiency for lead items. Detectors scan the bricks for contamination, and if found radioactive, the bricks are pushed on to a separate container. The contaminated bricks are then dumped as mixed waste, and the uncontaminated ones are collected in a separate container for reuse.

Cost-benefit analysis of an automated system was performed. The cost analysis is based on managing 1,000,000 $\mathrm{lbs}$ of lead bricks under three different scenarios: 1) the work for characterization and disposal of lead is given to a contractor; 2) FIU is the prime contractor; and 3 ) no characterization is performed, and all bricks are disposed of as radioactive waste. For each option two cases were considered: case $1,50 \%$ of the lead bricks are assumed contaminated, and case 2, 20\% of the bricks are contaminated. For each of the two cases, cost saving obtained if the characterization and disposal are performed by a contractor or by FIU over disposal of the entire quantity, without characterization, as waste is performed. The analysis shows that for $20 \%$ contaminated bricks a maximum saving of $\$ 3,162,200$ occurs if characterization is performed by FIU. It is estimated that with the assay time of 1.5 minutes for each brick weighing 60 pounds, the time needed to assay 1 million pounds of lead bricks will be 70 working days if the system is run 6 hours per day. 



\subsection{INTRODUCTION}

The United States Department of Energy (DOE) continually seeks safer and more cost-effective remediation technologies for use in the decontamination and decommissioning (D\&D) of its nuclear facilities. Decommissioning a nuclear facility generates an enormous amount of waste with very low level of contamination. At many of the DOE facilities, large quantities of metal are present, which need to be disposed of in a cost-effective way. Of particular concern is lead. Resource Conservation and Recovery Act (RCRA) requires lead to be managed as a hazardous waste if it is no longer providing its intended use. The Idaho National Engineering and Environmental Laboratory (INEEL) has more than 7 million pounds of lead in different forms. The INEEL has established an emergency reserve volume of 131 tons (about 300,000 pounds) of lead, which is in storage for emergency use in a radiological emergency requiring shielding. This volume is exempt from RCRA requirements. Volume greater than this amount that appears to be in storage and is not providing its intended purpose may be considered by a regulator to be in non-compliance. An exemption within RCRA allows lead to be managed as product if a recycling program is shown to be in place. An effective recycling program, which is moving lead to the scrap metal industry, must be in place to prevent potential Notices of Violation. DOE orders require materials that have been in radiological control areas be certified to have "NO DOE RAD ADDED" contamination before they can be recycled.

Lead in the form of shot, bricks, plates, and sheeting was and is used as shielding at all DOE sites to reduce worker exposure from gamma emitting sources. Lead forms can become volumecontaminated as a result of being formed from surface-contaminated lead or as a result of activation in shielding conditions. Because of the self-shielding attributes of lead (resulting from its high density and high atomic number), traditional contamination survey techniques are not effective in surveying the internal volume of lead forms. Current characterization techniques for determining internal volume contamination require physical samples to be extracted from the interior volume of lead items and laboratory analysis. This characterization technique is timeconsuming, increases personal lead exposure, delays lead disposition determinations, increases lead laboratory sample management, increases analysis data management, does not provide 100 $\%$ lead item sampling, costs $\$ 300$ per sample, does not validate surface survey results, and impedes recycling because of the above problems. In view of these difficulties in assessing contamination by conventional methods of sampling and analysis and in view of potential Notices of Violation, the DOE is in urgent need for cost-effective and efficient methods for performing volumetric radioassay of lead in different forms.

This report describes a system for handling and radioassay of lead, consisting of a robot, a conveyor, and a gamma spectrometer. The report also presents a cost-benefit analysis of options: radioassay and recycling lead vs. disposal as waste. 


\subsection{TECHNOLOGY NEED}

\begin{tabular}{|l|l|}
\hline Identification No. & Need Title \\
\hline ID-3.1.45 & $\begin{array}{l}\text { Volumetric Radioassay of Lead Sheet, Plate, Shot, and Irregular Shapes for } \\
\text { "NO DOE RAD ADDED" Determinations }\end{array}$ \\
\hline ID-7.2.16 & $\begin{array}{l}\text { Field Screening of Lead (shot, bricks, sheeting) for Radionuclide } \\
\text { Contamination }\end{array}$ \\
\hline AL-00-01-10-DD & Accelerated Real-Time Volumetric Radioassay of Lead Forms \\
\hline SR00-4007 & Characterization of Volumetric Contaminated Surfaces \\
\hline
\end{tabular}

There are more than seven million pounds of shielding lead in INEEL buildings, emergency shielding reserve storage, mixed waste storage, and in the operation surge storage. Approximately one million pounds has been identified as radiologically contaminated and placed into storage. The remaining lead still remains in operational and deactivated buildings or facilities and is awaiting decommissioning. A large percentage of this lead is not expected to be radiologically surface or volume contaminated.

There is a need for volumetric lead radioassays to determine whether millions of pounds of lead shielding, in storage at DOE sites, is free for release into recycling scrap metal industries. Much of this lead is believed not to be radiologically contaminated and will require some kind of field screening method so as to quantify how much of the lead is not contaminated and subject to release. Because of the self-shielding attributes of lead, traditional contamination survey techniques are not effective in surveying the internal volume of lead forms. Current characterization techniques for determining internal volume contamination require physical samples to be extracted from the interior volume of lead items and laboratory analysis. This characterization technique is time-consuming, increases personal lead exposure, delays lead disposition determinations, increases lead laboratory sample management, increases analysis data management, does not provide $100 \%$ lead item sampling, costs $\$ 300$ per sample, does not validate surface survey results, and impedes recycling because of the above problems.

The DOE requires a system with the following specifications:

- The system shall measure volumetric contamination.

- The system shall require no drilling of the lead.

- The system shall detect volumetric contamination with Cs-137 at a level of $1 \mathrm{pCi} / \mathrm{g}$ in a 30second count.

- The system shall detect gamma-ray emitters other than Cs-137 at a sensitivity range of 1 $\mathrm{pCi} / \mathrm{g}$.

- The system shall validate surface survey results and prevent a potential release of contaminated lead to the scrap metal industry.

- The methodologies for each of the requested lead forms shall be developed by the end of FY01. 
- The total cost for identifying the techniques specific for each lead form shall not exceed $\$ 40,000$. Alternatively, the cost of assay, including the instrumentation and labor, and disposal of only the fraction of the lead determined to be contaminated and recovery of revenue from the recycling of uncontaminated lead shall be less than the cost of disposal of the entire quantity of lead as a mixed waste (RCRA plus radioactive). 


\subsection{PROJECT TASKS}

The following tasks and milestones were scheduled for completion during FY00.

Task 1. Specific Review and Quantification of DOE Volumetric Lead Assay Needs With the enormous quantities of lead shielding material stored at many DOE sites, there is a need to conduct an overall assessment of how much is actually contaminated, so as to recycle the uncontaminated portion. This review will of course cut down on disposal costs. It is believed that most of the stored shielding material is not contaminated and needs to be quantified.

Information about the quantities of lead at INEEL was collected and is presented in Table 1.

\section{Task 2. Performance and Evaluation of Current Characterization Technologies}

FIU-HCET will select characterization technologies currently in use at DOE facilities storing lead. This will be done through review of commitment documents such as remediation plans and through direct interactions with the individuals responsible for the restoration and remediation activities. Vendors will also be evaluated at FIU-HCET.

Information about the survey instruments used for measurement of contamination was obtained from INEEL. A sodium iodide (Tl) based gamma radiation measuring system was developed at INEEL for volumetric surveying of lead bricks. Best efforts to get a copy of the report on this instrument were not successful. So FIU-HCET procured a gamma spectrometric system using broad energy germanium (BEGe) detectors and gained experience with this system and evaluated it. This system was used along with in-situ object counting software (ISOCS) for identification and quantitative assessment of rationuclides. FIUHCET also procured a sodium iodide based detector, which can be run on the same electronic system as the BEGe detector.

Task 3. Technology Performance and Uncertainties

A description of the technical specifications and the applicability of each technology to the site needs will be reported. This technical evaluation will identify gaps and uncertainties (if any) of the technologies with respect to their DOE mission. Identification of these uncertainties and solutions to reduce these as well as issues such as technology accuracy, reliability, failure rates, and extents will be dealt with explicitly. The occupational safety factor will also be assessed.

As stated in task, a BEGe based system was evaluated for its performance. Using this system along with ISOCS, activity of standard $10 \mathrm{~cm}$ x $10 \mathrm{~cm}$ Cs-137 and Co-60 sources placed at a distance was determined and found to match with the reference value (Fig. 3). This system also detects the small quantity of naturally occurring radionuclides present in materials, such as lead bricks and lead wool or building materials (Figs. 4-5). 


\section{Task 4. Recommendations of Technologies for System Integration}

FIU-HCET's CMST program will perform systems' integration as the most costeffective means of adapting commercial technologies to DOE's needs.

An integrated system composed of a robot, a conveyor, and BEGe detector based gamma spectrometric system was recommended. The sodium iodide system will be used when the gamma energy lines are well separated and also for comparison with the INEEL method.

\section{Task 5. System Design of Modules}

Delivery of a system design will identify the most appropriate technologies' combination that addresses DOE site users' needs.

A system design with cost comparison of various alternatives was performed and is presented.

\section{Task 6. Year-End Report}

A year-end report consisting of the work performed and combining all results and studies in a comprehensive report will be prepared.

This is the FY00 Year-End Report. Because of DOE's moratorium on disposal of radioactively contaminated metal to the scrap metal industry, this project on radioassay of lead will not continue in FY01. Therefore, this year-end report will be the final report on the project. 


\subsection{PROJECT MILESTONES}

C013-M1 Preliminary Report on Evaluation of Results, and Initial Design to allow Determination of Building Full System and Deploying at DOE sites

C013-M2 Report on Evaluation of HCET and Commercial Radiation Sensor Systems and Design of Optimal Radioassay Lead System

Both project milestones were completed on time.
Due Date:

June 1, 2000

Due Date:

September 6, 2000 


\subsection{TECHNOLOGY SUMMARY}

Lead is present in large quantities in DOE facilities. At INEEL alone more than 7 million pounds of lead is present. A significant fraction (more than 50\%) of lead is estimated not to be contaminated. Unless it is demonstrated to be free from contamination, lead must be assumed contaminated and disposed of as a mixed waste. Disposal of large quantities of lead is expensive and poses an environmental hazard. It also does not take advantage of recycling, which would provide monitoring dividends during the disposition of lead.

Cost-benefit analysis of an automated system, requiring a minimum amount of manpower and thus reducing exposure of human beings to radiation or to airborne lead particles, was performed. The system segregates uncontaminated lead from contaminated lead and thus makes it available for reuse. The system consists of a robotic gripper that picks up lead bricks from a stack and places them on a conveyor. BEGe based detectors mounted on the conveyor scan the bricks for contamination, and if found radioactive, the bricks are pushed on to a separate container. The contaminated bricks are then dumped as mixed waste, and the uncontaminated ones are collected in a separate container for reuse.

BEGe spectrometer with ISOCS is used for identification of gamma emitting radionuclides and for determination of their activities. The ISOCS software performs calculation of counting efficiency of objects of different shapes (planes, cylinders, boxes, spheres, etc.) placed at different distances from the detector, thus dispensing with the need for calibration with sources of identical configurations.

The time taken for placing a brick on the conveyor is 1.5 minutes. During this time, scan of the previously placed brick is completed. It is estimated that at a scanning rate of one brick of 60 pounds in 1.5 minute, the time needed to assay 1 million pounds of lead bricks will be 70 working days if the system is run 6 hours per day.

Various scenarios with different percentages of uncontaminated lead bricks are considered, and estimates of the projected savings are made. 


\subsection{BENEFITS}

The development of a real-time volumetric radioassay will provide the following:

- Fast and inexpensive determination of lead available for reuse and not requiring disposal. NO DOE RAD ADDED lead determination will not only save on the cost of disposal but also provide revenue due to recycling of lead.

- Low occupational exposure to lead.

- Accelerated disposition of entire difficult radioactive lead waste stream. 


\subsection{CAPABILITIES/LIMITATIONS}

FIU-HCET has built and used a system for in-situ decontamination and characterization of largebore pipes. The characterization system uses a gamma spectrometric system with four BEGe detectors on a conveyor and an in-situ object counting system (ISOCS) software. The detectors are arranged so that two detectors are above and two below the pipe, which moves on the conveyor at a preset speed. The radioassay trailer will be useful as a test bed for this project and will be similar to the expected final lead assay system design. Instead of running a large number of large-bore pipes on a conveyor belt through a radioassay trailer to determine if the pipes are clean, the characterization system will convey lead bricks and other lead forms through to determine whether there is any radioactivity added to the lead material. FIU-HCET personnel were first familiarized with the operation of the gamma spectrometric system and use of ISOCS software for pipe characterization and performed measurements on pipes at a nuclear power plant. Its use was evaluated for determination of NO DOE RAD ADDED for recycling.

Limitations on radioassay of lead are its high density and high atomic number; it also exists in different forms and provides self-shielding. Presence of radionuclides inside thick lead materials, particularly TRU, makes their detection difficult because of the low amounts (and low energy) of gamma rays emitted in the radioactive decay process. 


\subsection{ACCOMPLISHMENTS}

- Reviewed technologies for handling large quantities of lead.

- Procured a sodium iodide (Tl) spectrometric system for comparison with DOE method. Also procured a BEGe based gamma spectrometric system with ISOCS for identification of various multiple peaks in the gamma spectrum and for calculation of counting efficiency for different source configurations.

- Received a list of the quantity of lead in different forms available at INEEL. The information has recently been compiled.

- Used BEGe gamma spectrometer with conveyor system and ISOCS system for radioassay of large bore pipes. Evaluated the usefulness of this system for lead assay.

- Performed design of the automatic lead assay system composed of a robot, conveyor, and detection system.

- Performed cost-benefit analysis of the different options for characterization of lead for contamination, recycling the uncontaminated lead, and disposing as waste only the contaminated lead as against disposal of all lead as radioactive waste. 


\subsection{SYSTEM OPERATION}

The system consists of a set of four BEGe detectors, a conveyor, and a gantry robot to lift lead bricks from the pallet and place them on the conveyor.

\section{OPERATION STEPS}

- The lead bricks are stacked near the gantry robot.

- The gantry robot picks a lead brick one at a time from the pallet and places it on the conveyor.

- The lead brick then moves along the conveyor to BEGe detector chamber, which detects the brick for radioactivity.

- If the brick is radioactive, a sensor placed on the conveyor activates the product pusher, which pushes the brick into a container.

- If the brick is not radioactive, the sensor does not activate the product pusher, and therefore the lead brick moves to the end of the conveyor and falls into another container.

- Time for one lead brick to run through this system is 1.5 minutes.

The above-mentioned operation can be better understood with the help of Fig. 1.

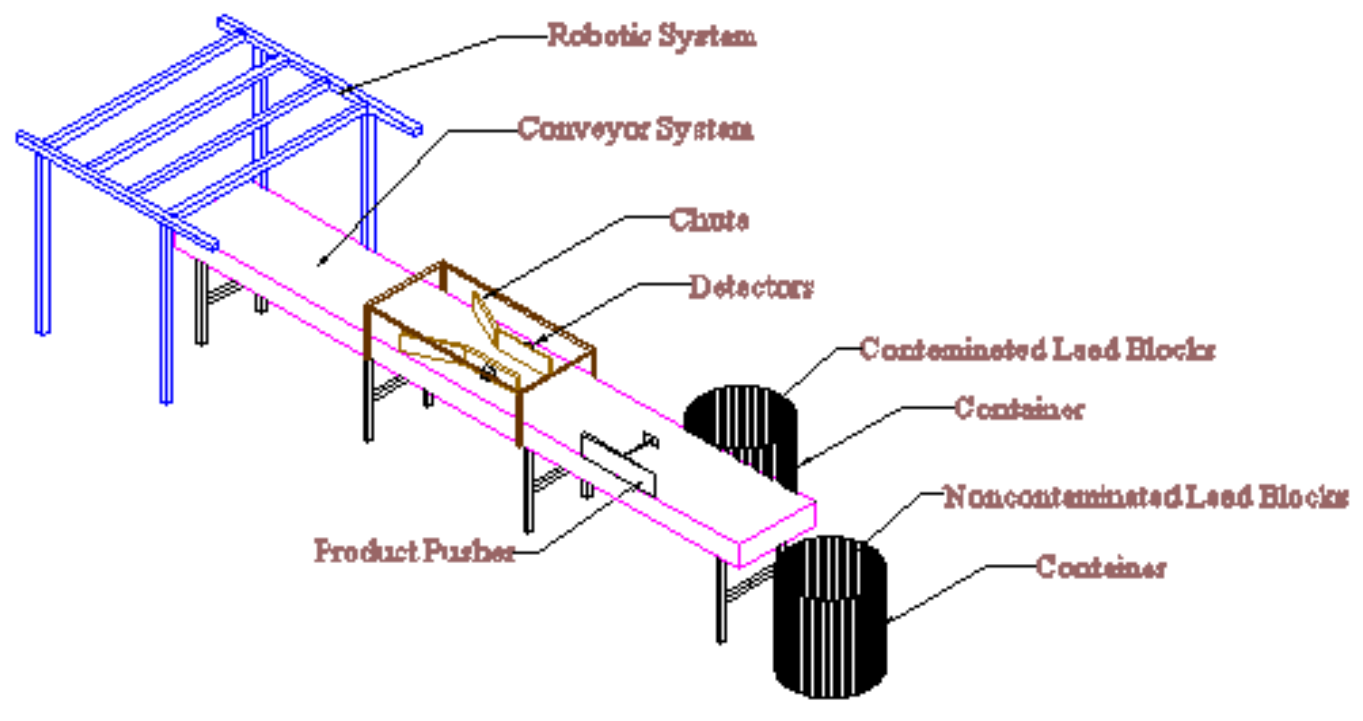

Schenetle tor Volunotrle Leed Arring syaton

Fig. 1 Volumetric lead assay system, showing a robotic system, conveyor, characterization system, and lead collection containers. 


\subsection{SYSTEM SPECIFICATIONS}

A number of vendors and their products for various system components (conveyor, robot and gamma spectrometer) were considered. Those considered to meet the requirements of low cost and good performance were selected and are described in this report.

\section{CONVEYOR SYSTEM FROM SHUTTLEWORTH, INC.}

The lead bricks are loaded onto the conveyor system individually from the gantry robot at a rate of one brick every 30 seconds. The system is designed to convey lead bricks to the blade stop on Unit \#1, where the customer's supplied equipment will detect the block's radioactivity.

If the brick is radioactive, a sensor placed on the conveyor activates the product pusher, which pushes the brick into a container. If the brick is not detected for radioactivity, the sensor won't activate the product pusher, and therefore the lead brick moves to the end of the conveyor and falls into another container.

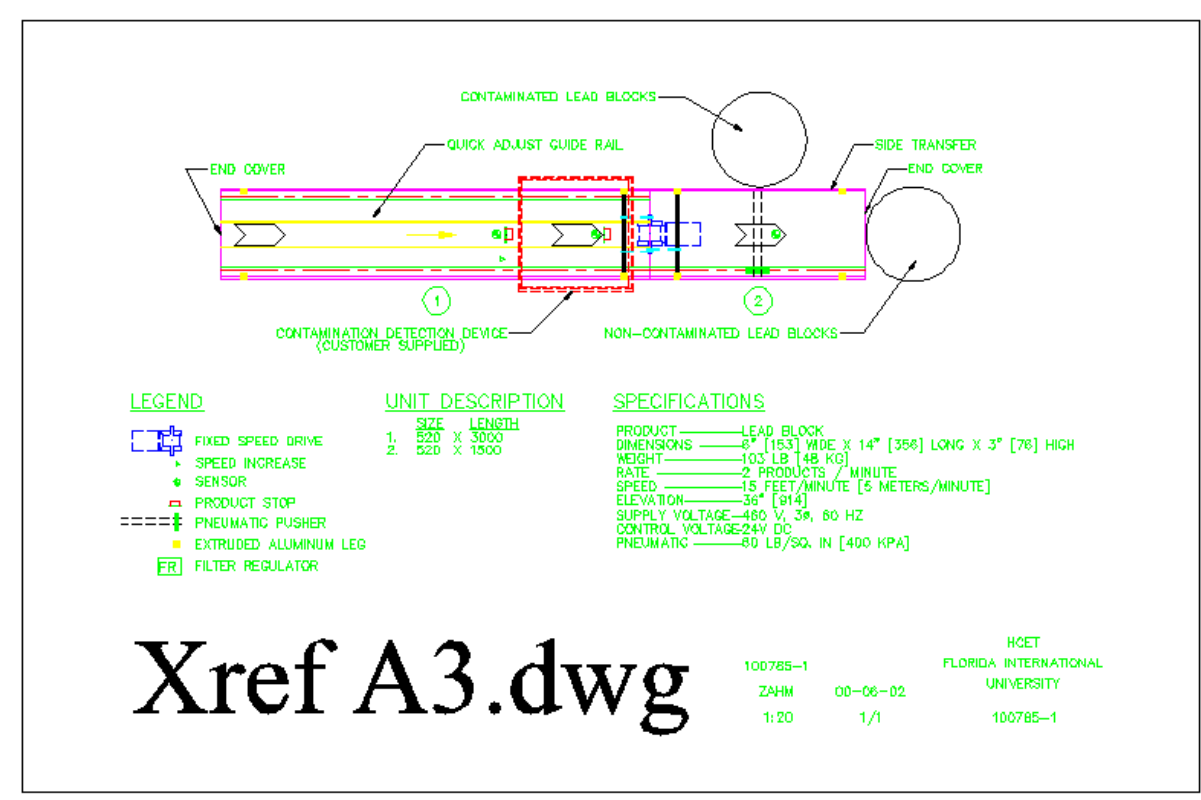

Fig. 2 Lead characterization system with details.

Conveyor Type:

Roller Diameter:

Rollershaft Center:

Roller Type:

Guiderail:

Support Style:

\section{Mechanical specifications of the conveyor}

Slip-Torque, Aluminum Side Rail, Chain Driven, Spec 1041

Standard Pitch, $21 \mathrm{~mm}$

$22.7 \mathrm{~mm}$

Solid Black Low Friction

Low Profile Plastic, Spec. 3081

Extruded Aluminum 


\section{PNEUMATIC SPECIFICATIONS OF THE CONVEYOR}

All pneumatic devices are provided with a 4-way, 5-port solenoid operated valve, installed and piped to the pneumatic device using polyethylene tubing. A filter/regulator unit is provided. If more than one pneumatic device is supplied, the devices will be piped to a common point using polyethylene tubing. All exhaust ports are vented to atmosphere. Pneumatic device and header layout diagrams will be provided, if applicable.

\section{ELECTRICAL SPECIFICATIONS OF THE CONVEYOR}

All electrical devices will be installed and terminated to the control panel. Control logic will be included. A non-dimensioned component layout, wiring schematic, software documentation, and panel layout will be provided with the system. The system will be wired according to Shuttleworth, Inc. standard wiring practices and the National Electrical Code.

\section{GANTRY ROBOT FROM PARKER HANNIFIN CORPORATION, DAEDAL DIVISION}

The gantry robot, which is placed in front of the conveyor, picks lead bricks from the pallet and places them on the conveyor one at a time. Time to pick one lead brick and place it on the conveyor is approximately 30 seconds. The Robotic System consists of

- HLE Linear Drive Module

- Vertical Drive Module

- Cable System Management

- Home Position Sensors

- Travel Limit Sensors

- Gear Reducers

- Structural Frame

- Servo Motor System

- Robotic Arms for lifting the lead bricks.

\section{GERMANIUM DETECTORS FROM CANBERRA, INC.}

The following are the accessories with the broad energy germanium detectors:

- ISOCS Characterization for new CI Detectors

- Flanged Big Mac

- Remote detector chamber

- MAC fill device

- Dewar (30 liter)

- Detector frame and Assembly 
- Inspector 2000 DSP portable MCA and accessories

- Genie-2000 Software and accessories

- Genie-2000 Interactive peak fit

- IBM Computer and accessories

- Liquid Nitrogen. 


\subsection{COST ANALYSIS}

This section provides a cost analysis that compares the costs of using a new approach (radioassaying, recycling/ disposing lead bricks) with the baseline method of disposing all bricks as radwaste. The cost analysis is based on managing 1,000,000 lbs of lead bricks under three different scenarios. Three options (option A, option B and option C) are considered. Option A is giving the contract for characterization and disposal of lead to any contractor. In option B, FIUHCET is the prime contractor. In option $\mathrm{C}$, all bricks are disposed of as radioactive waste. For each option two cases were considered - (case 1 and case 2). In case 1,50\% of the lead bricks are assumed contaminated. In case 2, 20\% of the bricks are contaminated. Option A, which is giving the contract characterization and disposal of lead to any contractor, nets a saving of $\$ 1,650,550$ if $50 \%$ of the bricks are contaminated and a saving of $\$ 2,940,550$ if $20 \%$ of the bricks are contaminated. Option B, where FIU-HCET is the prime contractor, nets a saving of $\$ 1,872,200$ if $50 \%$ of the bricks are contaminated and a saving of $\$ 3,162,200$ if $20 \%$ of the bricks are contaminated. Option $\mathrm{C}$, where all bricks are disposed off as radwaste, does not have a saving. Considering that the system is run $6 \mathrm{hrs}$ per day and the weight of the lead brick is $60 \mathrm{lbs}$. (12inch $\times$ 4-inch x 3 -inch brick), then the number of days to assay all bricks is 70 days. This is calculated by taking into consideration the time for one lead brick to run through the system is 1.5 minutes.

The schematic cost structure and profit margin calculation for this system can be found in Appendix A. The operating costs and the costs of various equipments can be found in Appendix B.

\section{COST ANALYSIS CONCLUSION}

Option A:

If $50 \%$ of bricks are contaminated $=$ net savings of

$\$ 1,650,550$

If $20 \%$ of bricks are contaminated $=$ net savings of

$\$ 2,940,550$

Option B:

If $50 \%$ of bricks are contaminated $=$ net savings of

If $20 \%$ of bricks are contaminated $=$ net savings of

$\$ 1,872,200$

$\$ 3,162,200$

Option C:

Cost of disposing all lead bricks

$\$ 4,000,000$

Option $\mathrm{C}$ does not save anything. 

SCHEMATIC COST STRUCTURE AND PROFIT MARGIN FOR VOLUMETRIC LEAD ASSAY SYSTEM 



\section{OPTION A: GIVING THE CONTRACT TO ANY CONTRACTOR}

Bricks to be detected for contamination:

Weight of one brick: $60 \mathrm{lbs}$

Therefore, total number of bricks $=$

Number of hours the system is run per day: 6 hours $=$ Worst case time for one lead brick to run through the system:

Therefore, number of bricks assayed per day $=$

Number of days to assay all bricks: 16,700/240=
$1,000,000 \mathrm{lbs}$

$1,000,000 / 60=16,700$ bricks

360 minutes

1.5 minutes

$360 / 1.5=240$ bricks/day

70 days

\section{Costs}

Cost of the four detectors

Cost of the conveyor system

Cost of the robotic system

Miscellaneous and maintenance expenses

Labor cost for characterization (APPENDIX B)

Labor cost for system assembly and testing (APPENDIX B)

Cost of filling liquid nitrogen

Total Equipment and Operating Costs
$\$ 221,650$

$\$ 45,000$

$\$ 45,000$

$\$ 10,000$

$\$ 44,800$

$\$ 32,000$

$\$ 1,000$

\section{CASE 1. 50\% OF BRICKS ARE CONTAMINATED}

Option 1: Characterize, dispose contaminated bricks and recycle uncontaminated bricks.

Cost of disposing lead bricks

Cost of selling uncontaminated lead bricks

Cost of shipping bricks $=\$ 0.10 /$ pound
$\$ 4.00 /$ pound

$\$ 0.30 /$ pound

$\$ 399,450$

Cost of disposing 500,000 lbs contaminated bricks $=500,000 \times \$ 4=\$ 2,000,000$

Cost of shipping 1,000,000 lbs contaminated bricks $=1,000,000 \times \$ 0.10=\$ 100,000$

Recovery of costs by selling 500,000 lbs uncontaminated bricks $=500,000 \times \$ 0.30=\$ 150,000$

Total cost of disposing $=\$ 2,000,000+\$ 100,000-\$ 150,000=\$ 1,950,000$

Total equipment and operating costs $=\$ 399,450$

Total costs $=\$ 1,950,000+\$ 399,450=\$ 2,349,450$ 


\section{Option 2: All bricks are disposed as radioactive waste}

Cost of disposing lead bricks $1,000,000$ lbs $x \$ 4.00=\$ 4,000,000$

Therefore, Net Saving by using Option 1 as against Option $2=\$ 4,000,000-\$ 2,349,450=$ $\$ 1,650,550$

\section{CASE 2. 20\% OF BRICKS ARE CONTAMINATED}

Option 1: Characterize, dispose contaminated bricks and recycle uncontaminated bricks.

Cost of disposing lead bricks $=$

Cost of selling uncontaminated lead bricks $=$

Cost of shipping bricks $=$
$\$ 4.00 /$ pound

$\$ 0.30 /$ pound

$\$ 0.10 /$ pound

Cost of disposing 200,000 lbs contaminated bricks $=200,000 \times \$ 4=\$ 800,000$

Cost of shipping 1,000,000 lbs of contaminated bricks $=1,000,000 \times \$ 0.10=\$ 100,000$

Recovery of costs by selling $800,000 \mathrm{lbs}$ uncontaminated bricks $=800,000 \times \$ 0.30=\$ 240,000$

Total cost of disposing $=\$ 800,000+\$ 100,000-\$ 240,000=\$ 660,000$

Total equipment and operating costs $=\$ 399,450$

Total costs $=\$ 660,000+\$ 399,450=\$ 1,059,450$

\section{Option 2: All bricks are disposed as radioactive waste}

\section{Cost of disposing lead bricks $1,000,000 \mathrm{lbs} \times \$ 4.00=\$ 4,000,000$}

Therefore, net saving by using Option 1 as against Option $2=\$ 4,000,000-\$ 1,059,450$

$$
=\$ 2,940,550
$$

Schematic Cost Structure and Profit Margin for Volumetric Lead Assay System

\section{OPTION B: FIU-HCET IS PRIME CONTRACTOR}

FIU-HCET has four detector systems that amount to a savings of $\$ 221,650$. So, the cost of buying new systems is reduced.

Bricks to be detected for contamination: $\quad 1,000,000 \mathrm{lbs}$

Weight of one brick: $60 \mathrm{lbs}$

Therefore $\quad 1,000,000 / 60=\quad 16,700$ bricks 
No of hours the system is going to run: $6 \mathrm{hrs}=$

Worst case time for one lead brick to run through the system:

Therefore $\quad 360 / 1.5=$

Number of days to assay all bricks: $16,700 / 240=$

Cost of the Conveyor system $=$

Cost of the Robotic System $=$

Miscellaneous and Maintenance Expenses =

Labor Cost for Characterization $=$

Labor Cost for System Assembly and Testing =

Cost of Filling Liquid Nitrogen $=$

Total Equipment and Operating Costs=
360 minutes

1.5 minutes

$240 \mathrm{bricks} /$ day

70 days

$\$ 45,000$

$\$ 45,000$

$\$ 10,000$

$\$ 44,800$

$\$ 32,000$

$\$ 1,000$

$\$ 177,800$

\section{CASE 1. 50\% OF BRICKS ARE CONTAMINATED}

Option 1: Characterize, dispose contaminated bricks and recycle uncontaminated bricks.

Cost of disposing lead bricks $=$

Cost of selling uncontaminated lead bricks $=$

Cost of shipping bricks $=\$ 0.10$ pound
$\$ 4.00 /$ pound

$\$ 0.30 /$ pound

Cost of disposing 500,000 lbs contaminated bricks $=500,000 \times \$ 4=\$ 2,000,000$

Cost of shipping 1,000,000 lbs contaminated bricks $=1,000,000 \times \$ 0.10=\$ 100,000$

Recovery of costs by selling 500,000 lbs uncontaminated bricks $=\quad 500,000 \times \$ 0.30$

$=\$ 150,000$

Total cost of disposing $\$ 2,000,000+\$ 100,000-\$ 150,000=$ $\$ 1,950,000$

Total equipment and operating costs $=$ $\$ 177,800$

Total costs $=\$ 1,950,000+\$ 177,800=$ $\$ 2,127,800$ 


\section{Option 2: All bricks are disposed as radioactive waste}

Cost of disposing lead bricks $1,000,000$ lbs $\times \$ 4.00=$

$\$ 4,000,000$

Therefore, Net Saving by using Option 1 as against Option $2=\$ 4,000,000-\$ 2,127,800$

$$
=\$ 1,872,200
$$

\section{CASE 2. 20\% OF BRICKS ARE CONTAMINATED}

Option 1: Characterize, dispose contaminated bricks and recycle uncontaminated bricks.

Cost of disposing lead bricks $=$

Cost of selling uncontaminated lead bricks $=$

Cost of shipping bricks $=\$ 0.10 /$ pound
$\$ 4.00 /$ pound

$\$ 0.30 /$ pound

Cost of disposing 200,000 lbs contaminated bricks $=200,000 \times \$ 4=\quad \$ 800,000$

Cost of shipping 1,000,000 lbs contaminated bricks $=1,000,000 \times \$ 0.10=\$ 100,000$

Recovery of costs by selling 800,000 lbs uncontaminated bricks $=800,000 \times \$ 0.30=\$ 240,000$

Total cost of disposing $\$ 800,000+\$ 100,000-\$ 240,000=\quad \$ 660,000$

$\begin{array}{ll}\text { Total equipment and operating costs }= & \$ 177,800\end{array}$

Total costs $=\$ 660,000+\$ 177,800=$

$\$ 837,800$

\section{Option 2: All bricks are disposed as radioactive waste}

Cost of disposing lead bricks $1,000,000 \mathrm{lbs} \times \$ 4.00=\quad \$ 4,000,000$

Therefore, Net Saving by using Option 1 as against Option $2=\$ 4,000,000-\$ 837,800$

$=\$ 3,162,200$

\section{OPTION C: ALL BRICKS ARE DISPOSED AS RADWASTE}

Bricks to be disposed: 1,000,000 lbs

Cost of disposing lead bricks $=\$ 4.00 /$ pound

Cost of disposing lead bricks $1,000,000$ lbs $x \$ 4.00=\$ 4,000,000$ 


\section{COST ANALYSIS SUMMARY}

Option A:

If $50 \%$ of bricks are contaminated= net savings of $\mathbf{\$ 1 , 6 5 0 , 5 5 0}$

If $20 \%$ of bricks are contaminated= net savings of $\$ \mathbf{2 , 9 4 0 , 5 5 0}$

Option B:

If $50 \%$ of bricks are contaminated $=$ net savings of $\mathbf{\$ 1 , 8 7 2 , 2 0 0}$

If $20 \%$ of bricks are contaminated= net savings of $\mathbf{\$ 3 , 1 6 2 , 2 0 0}$

Option C:

Cost of disposing all lead bricks $=\$ \mathbf{4 4 , 0 0 0 , 0 0 0}$

Option $\mathrm{C}$ does not save anything. 



\section{APPENDIX B}

\section{FOUR DETECTORS AND ACCESSORIES QUOTED BY CANBERRA}





\begin{tabular}{|c|c|c|c|c|}
\hline Item & Description & Quantity & Unit Price & Extended Total \\
\hline 1 & Broad Energy Germanium Detectors & 4 & $\$ 33,000$ & $\$ 132,000$ \\
\hline 2 & $\begin{array}{l}\text { ISOCS Characterization for new } \\
\text { CI Detectors }\end{array}$ & 1 & $\$ 7,500$ & $\$ 7,500$ \\
\hline 3 & Flanged Big Mac & 4 & $\$ 1,250$ & $\$ 5,000$ \\
\hline 4 & Remote detector chamber (4" neck) & 4 & $\$ 1,000$ & $\$ 4,000$ \\
\hline 5 & MAC fill device & 1 & $\$ 500$ & $\$ 500$ \\
\hline 6 & Dewar (30 liter) & 4 & $\$ 700$ & $\$ 2,800$ \\
\hline 7 & $5 \mathrm{~cm}$ Side Shield for detectors & 4 & $\$ 4,000$ & $\$ 16,000$ \\
\hline 8 & $5 \mathrm{~cm}$ Back Shield for detectors & 4 & $\$ 1,600$ & $\$ 6,400$ \\
\hline 9 & Detector frame and Assembly & 4 & $\$ 7,200$ & $\$ 28,800$ \\
\hline 10 & $\begin{array}{l}\text { Inspector } 2000 \text { DSP portable MCA } \\
\text { and accessories }\end{array}$ & 1 & $\$ 9,000$ & $\$ 9,000$ \\
\hline 11 & $\begin{array}{l}\text { Genie-2000 Software and } \\
\text { accessories }\end{array}$ & 1 & $\$ 3,150$ & $\$ 3,150$ \\
\hline 12 & $\begin{array}{l}\text { Genie-2000 Interactive peak fit for } \\
\text { review results of automatic peak } \\
\text { search, add/delete peaks, modify fit } \\
\text { regions and graphic display of fits \& } \\
\text { residuals }\end{array}$ & 1 & $\$ 500$ & $\$ 500$ \\
\hline 13 & IBM Computer and accessories & 1 & $\$ 6,000$ & $\$ 6,000$ \\
\hline \multicolumn{4}{|l|}{ Total } & $\$ 221,650$ \\
\hline
\end{tabular}

\section{CONVEYOR SYSTEM AND ITS ACCESSORIES QUOTED BY SHUTTLEWORTH}

\section{Mechanical Specifications}

Conveyor type:

Rroller diameter:

Rollershaft center:

Roller type:

Guiderail:

Support style:
Slip-Torque, Aluminum Side Rail, Chain Driven, Spec 1041

Standard Pitch, $21 \mathrm{~mm}$

$22.7 \mathrm{~mm}$

Solid Black Low Friction

Low Profile Plastic, Spec. 3081

Extruded Aluminum

\section{PNEUMATIC SPECIFICATIONS}

\section{PNEUMATIC SUPPLY ONLY:}

All pneumatic devices are provided with a 4-way, 5-port solenoid operated valve, installed and piped to the pneumatic device using polyethylene tubing. A filter/regulator unit is provided. If more than one pneumatic device is supplied, the devices will be piped to a common point using polyethylene tubing. All exhaust ports are vented to atmosphere. Pneumatic device and header layout diagrams will be provided, if applicable.

Total Price of the Conveyor System and its Accessories as provided by Shuttleworth $=\$ 45,000$ 


\section{Robotic System and its Accessories as Quoted by Parker Hannifin Corporation}

The Robotic System consists of

- HLE Linear Drive Module

- Vertical Drive Module

- Cable System Management

- Home Position Sensors

- Travel Limit Sensors

- Gear Reducers

- Structural Frame

- Servo Motor System

- Robotic Arms for lifting the lead bricks.

Total Cost of the Robotic System as provided by Parker Hannifin Corporation $=\$ 45,000$

\section{Labor Cost for Characterization}

Taking into consideration that 2 persons would be working together for 70 days until the whole operation is completed

Number of working hours per person per day $=8 \mathrm{hrs} \times 2$ persons $=16 \mathrm{hrs}$ for two persons

Pay per hour per person $=\$ 40 / \mathrm{hr}=\$ 40 \times 16 \mathrm{hrs}$ for two persons $=\$ 640 /$ day $=\$ 44,800$ for the 70 days period for 2 persons

Therefore, Total Labor Cost for Two persons for the 70-day period $=\$ 44,800$

\section{Labor Cost for System Assembly and Testing}

Taking into consideration that 4 persons would be working together for 25 days for system assembling and testing

Number of working hours per person per day $=8 \mathrm{hrs} \times 4$ persons $=32 \mathrm{hrs}$ for four persons per day

Pay per hour per person $=\$ 40 / \mathrm{hr}=\$ 40 \times 32 \mathrm{hrs}$ for four persons $=\$ 1,280 /$ day $=\$ 32,000$ for the 25-day period for 4 persons

Therefore, Total Labor Cost for System Assembly and Testing $=\$ 32,000$ 


\section{Maintenance and Miscellaneous Expenses}

Taking into consideration that $16 \mathrm{hrs}$ of maintenance would be needed for the whole operation period of 70 days

Pay per hour taking into consideration all benefits $=\$ 40 / \mathrm{hr}=16 \mathrm{hrs} \times \$ 40=\$ 640$

Other expenses such as electricity, air-conditioning, additional equipment, spare parts, cost of buying new equipment if old equipment doesn't function, service charges, etc. $=\$ 9360$

Therefore, Total Maintenance and Miscellaneous Expenses $=\$ 9360+\$ 640=\$ 10,000$

\section{Cost of Filling Liquid Nitrogen and Expenses Involved in Filling}

Cost of Filling Liquid Nitrogen per week $=\$ 50 /$ week

Number of weeks the system will run $=14$ weeks

Therefore, Total Cost $=\$ 50 \times 14=\$ 700$

Operating and other expenses such as service charge, spare parts $=\$ 300$

Therefore, total cost of filling liquid nitrogen $=\$ 700+\$ 300=\$ 1000$ 

CONTACT INFORMATION 



\section{Conveyor System}

\section{Shuttleworth Inc.}

10 Commercial Road

Huntington, IN 46750-9044

Tel: 2193569044

Fax 2193597810

URL: www.shuttleworth.com

\section{Robotic System}

\section{Parker Hannifin Corporation}

Daedal Division

1140 Sandy Hill Road

Irwin, PA 15642

Tel: 18002456903

URL: www.daedalpositioning.com

\section{Detectors}

\section{Canberra Industries}

800 Research Parkway

Meriden, CN 06450

Tel: 2032382351

Toll Free: 18002434422

FAX: 2032351347

URL: www.canberra.com 
Table 1

Inventory of Lead at INEEL

Contaminated and uncontaminated lead (excess + in use $)=7,217,844 \mathrm{lbs}$.

Contaminated (excess + in use) $=2,943,071 \mathrm{lbs}$.

Amount of contaminated excess lead $=1,785,295 \mathrm{lbs}$.

Type and quantity of contaminated excess lead at INEEL

Type of Lead

Shot

Bricks

Chunks/Chips

Sheet

Wool

Bulk

Cask

Other
Quantity of Contaminated Excess Lead (lb)

94,298

100,531

15,339

36,680

208

765,829

292,139

480,271

Table 2

Summary of contamination values for unrestrictive free release

\begin{tabular}{|c|c|c|}
\hline Nuclide & $\begin{array}{l}\text { REMOVABLE } \\
\left(\mathrm{dpm} / 100 \mathrm{~cm}^{2}\right)\end{array}$ & $\begin{array}{l}\text { TOTAL (FIXED+REMOVABLE) } \\
\text { (dpm/100 cm²) }\end{array}$ \\
\hline $\begin{array}{l}\text { U-natural, U-235, U-228 and } \\
\text { associated decay products }\end{array}$ & 1,000 alpha & 5,000 alpha \\
\hline $\begin{array}{l}\text { Transuranics, Ra-226, Ra-228, } \\
\text { Th-230, Th-228, Pa-231, Ac- } \\
\text { 227,I-129 }\end{array}$ & 20 & 500 \\
\hline $\begin{array}{l}\text { Th-nat, Th-232, Sr-90, Ra-223, } \\
\text { Ra-224, U-232, I-125, I-125, I- } \\
\text { 126, I-131, I-133 }\end{array}$ & 200 & 1,000 \\
\hline $\begin{array}{l}\text { Beta-gamma emitters (nuclides } \\
\text { with decay modes other than } \\
\text { alpha emission or spontaneous } \\
\text { fission) except Sr-90 and others } \\
\text { noted above. Includes mixed } \\
\text { fission products containing Sr-90 }\end{array}$ & 1,000 beta-gamma & 5,000 beta-gamma \\
\hline $\begin{array}{l}\text { Tritium organic compounds, } \\
\text { surfaces contaminated by HT, } \\
\text { HTO and metal tritide }\end{array}$ & 10,000 & * 10,000 \\
\hline
\end{tabular}

Notes:

1. The values in this table apply to radioactive contamination deposited on, but not incorporated into the interior of the contaminated item. Where contamination by both alpha and beta-gamma emitting nuclides exists, the limits established for the alpha and beta-gamma emitting nuclides apply independently.

2. a. The amount of removable radioactive material per $100 \mathrm{~cm}^{2}$ of surface area should be determined by swiping the area with dry filter or soft absorbent paper while applying moderate 
pressure and then assessing the amount of radioactive material on the swipe with an appropriate instrument of known efficiency.

b. For objects with a surface area less than $100 \mathrm{~cm}^{2}$, the entire surface should be swiped, and the activity per unit area should be based on the actual surface area. Except for transuranics, Ra-228, Ac227, Th-228, Th-230, Pa-231, and alpha emitters, it is not necessary to use swiping techniques to measure removable contamination levels if direct scan surveys indicate that the total residual contamination levels are below the values for removable contamination.

3. The levels may be averaged over 1 square meter provided the maximum activity in any area of $100 \mathrm{~cm}^{2}$ is less than three times the values in the table.

Table 3

List of instruments used by INEEL technicians

\begin{tabular}{|c|c|c|}
\hline Type of Measurement & Instrument & Efficiency \\
\hline Beta/Gamma Contamination & $\begin{array}{l}\text { Ludlum Model 2A with } \\
\text { attached HP260 or HP210 } \\
\text { (shielded) GM detector }\end{array}$ & $\begin{array}{l}25-30 \% \text { for Cesium, 4-Pi, Near Contact } \\
10-15 \% \text { for Cobalt, 4-Pi, Near Contact } \\
30+\% \text { Strontium, 4-Pi, Near Contact }\end{array}$ \\
\hline Alpha Contamination & $\begin{array}{l}\text { NE Electra with attached } \\
100 \text { sq. } \mathrm{cm} \text { scintillation } \\
\text { detector }\end{array}$ & $\begin{array}{l}\text { 15\% for Cesium-137, 4-Pi, Near Contact } \\
\text { Dual Mode: } 16-18 \% \text { for Plutonium-239, 4-Pi, } \\
\text { Near Contact } \\
\text { Alpha Only Mode with AP5 } 100 \mathrm{~cm}^{2} \\
\text { scintillation detector attached: } 22-25 \% \text { for } \\
\text { plutonium-239, 4-Pi, Near Contact } \\
\text { Thorium } 230 \text { (used for U-328) } \\
1-2 \% \text { less than Plutonium-239 }\end{array}$ \\
\hline $\begin{array}{l}\text { Swipes for loose alpha and } \\
\text { beta/gamma contamination }\end{array}$ & $\begin{array}{l}\text { Tennelec LB-5100 } \\
\text { Protean MPC-9400 }\end{array}$ & $\mathrm{N} / \mathrm{A}$ \\
\hline
\end{tabular}




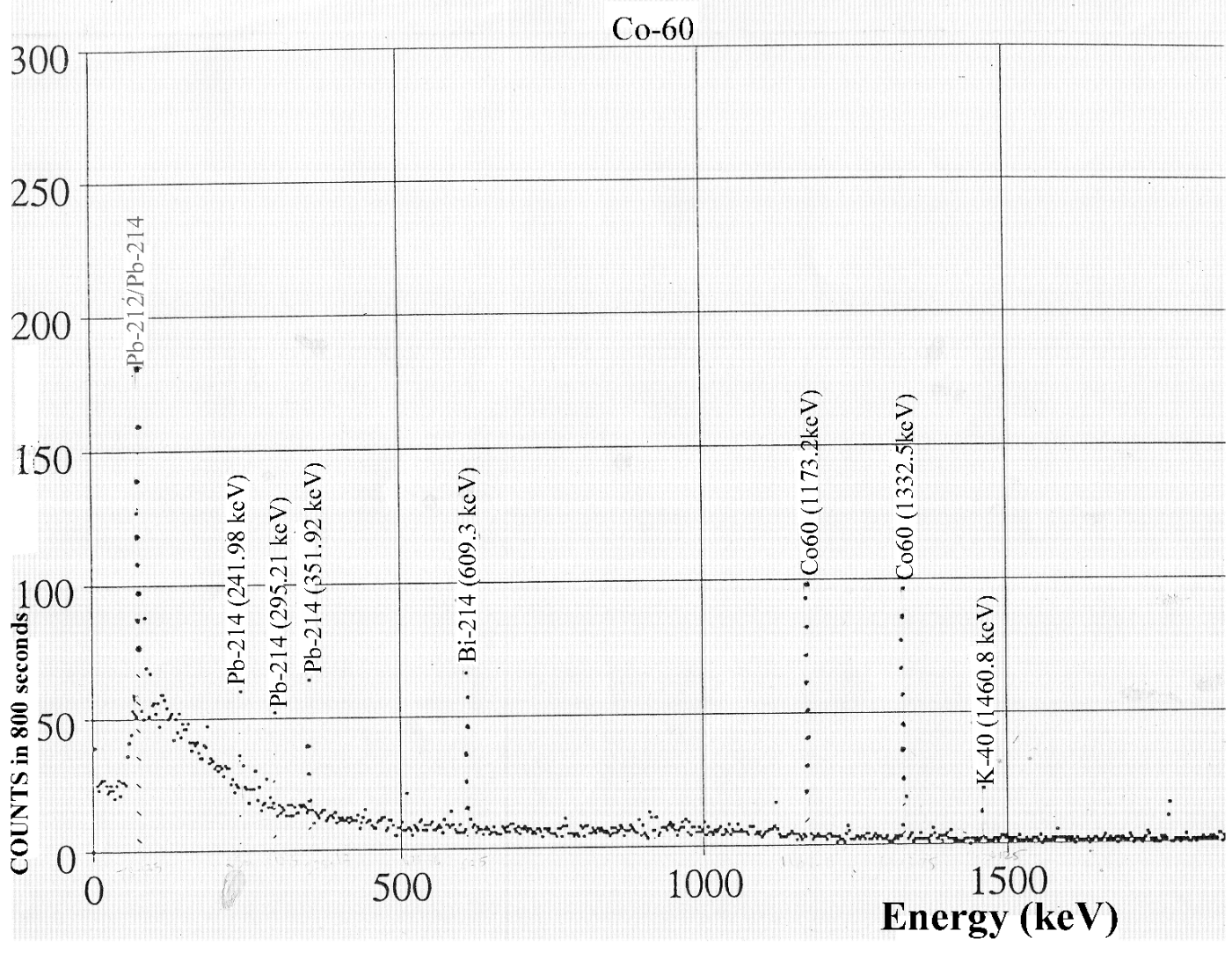

Fig. 3 Gamma spectrum obtained by placing a Co-60 standard source at a distance from the BEGe detector, showing Co-60 peaks, in addition to natural background radionuclides. 


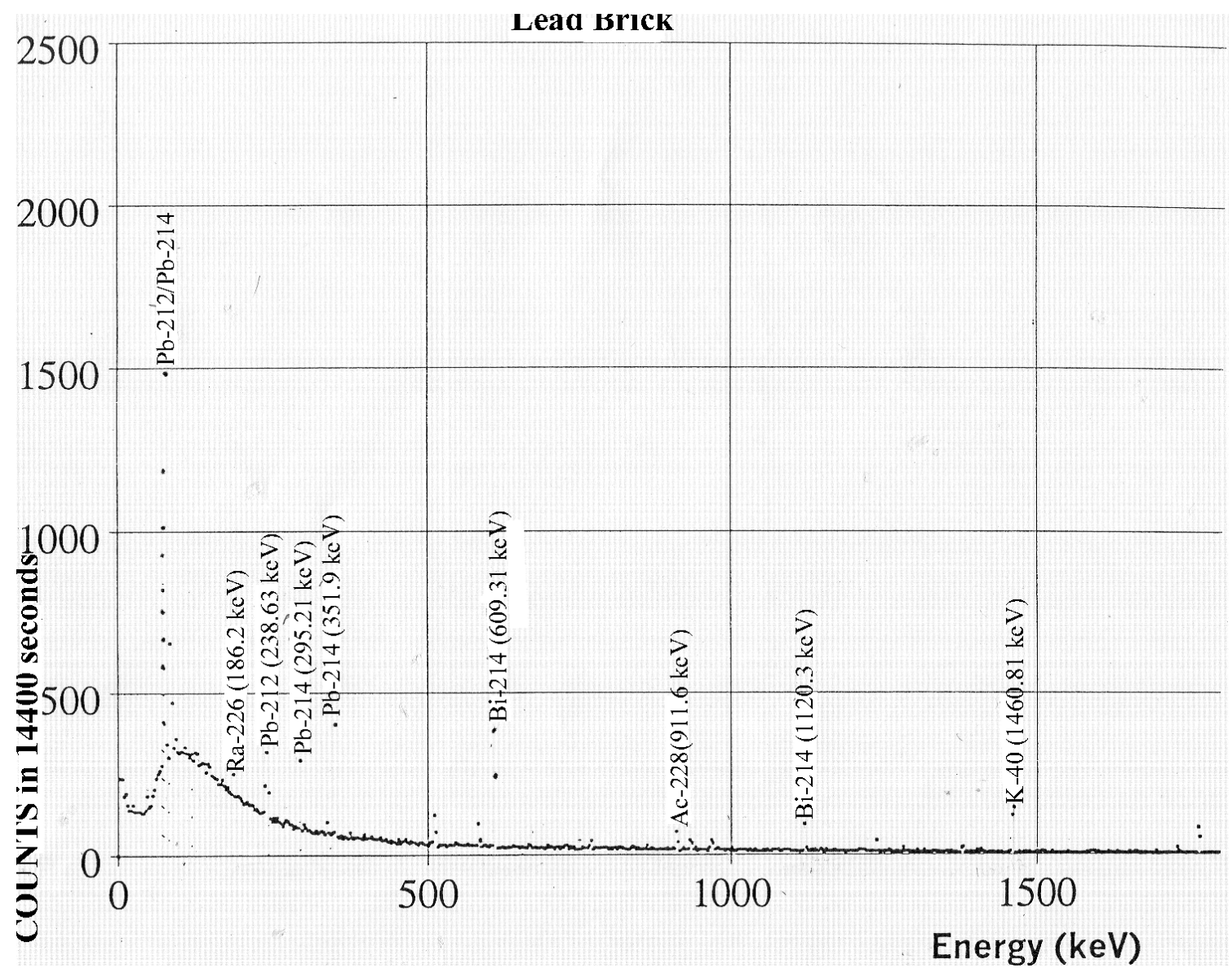

Fig. 4 Gamma spectrum obtained by placing a 12"x 4"x2" thick lead brick at a distance from the $B E G e$ detector, showing natural background radionuclides. 


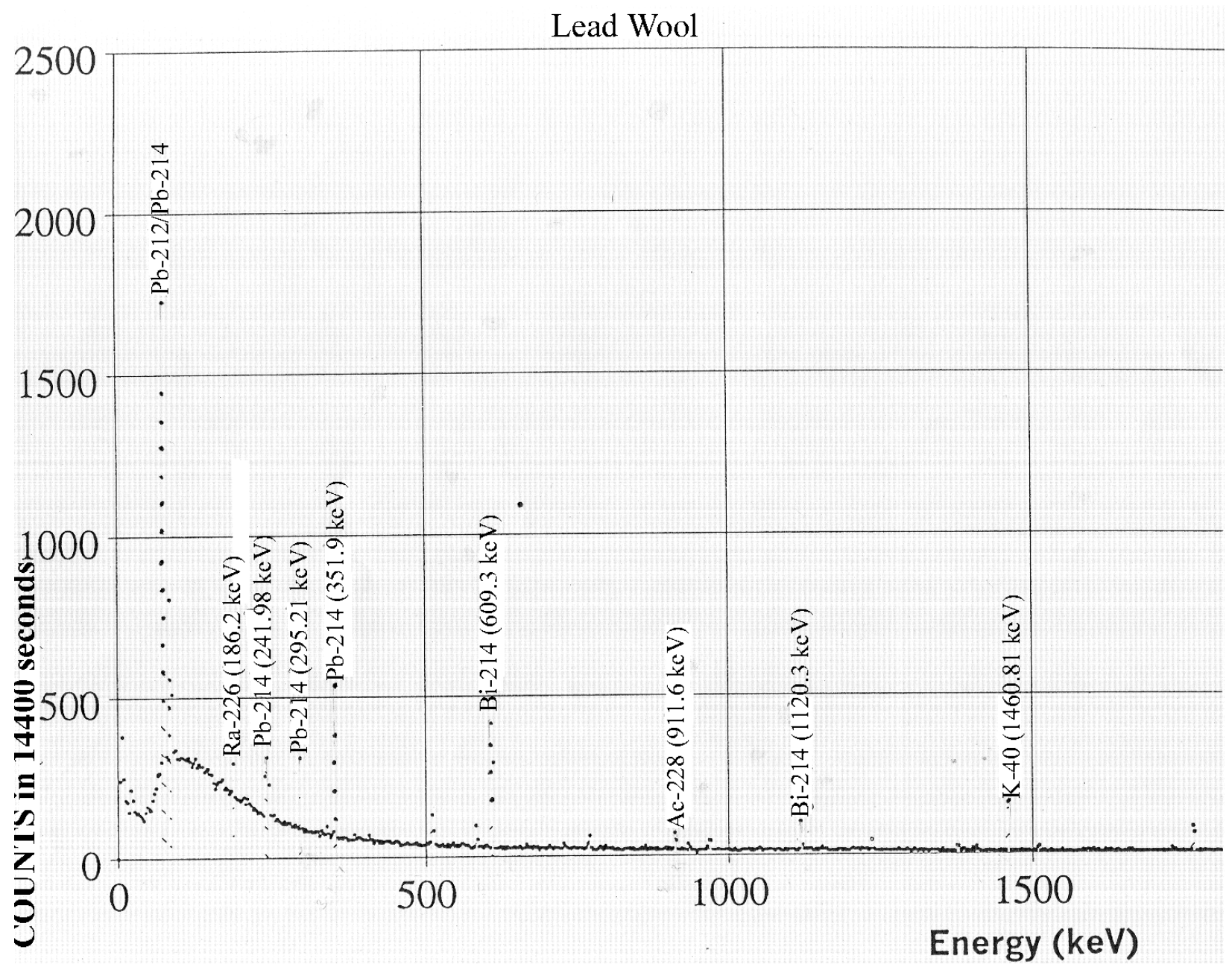

Fig. 5 Gamma spectrum obtained by placing 8"x8"x0.25" thick lead wool at a distance from the BEGe detector, showing natural background radionuclides. 